\title{
Gastric Intramucosal Carcinoma in a Small Hyper- plastic Foveolar Polyp
}

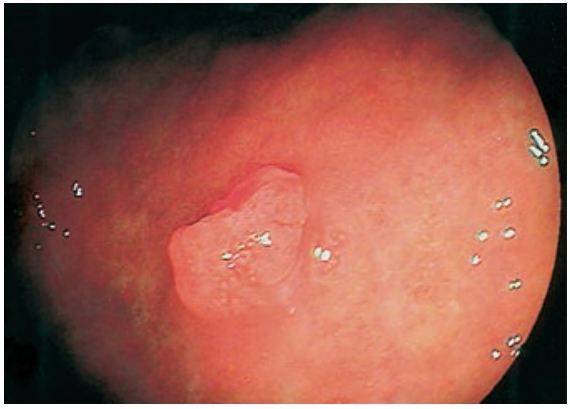

Figure 1 In this patient, upper gastrointestinal endoscopy revealed a 6-mm sessile elevated lesion in the greater curvature of the middle gastric body. The surface of the lesion was lobulated, and an erosion was noticed on the top. It was removed by electrosurgical snare polypectomy.

A. Okano, H. Takakuwa, Y. Matsubayashi Department of Gastroenterology, Tenri Hospital, Nara, Japan

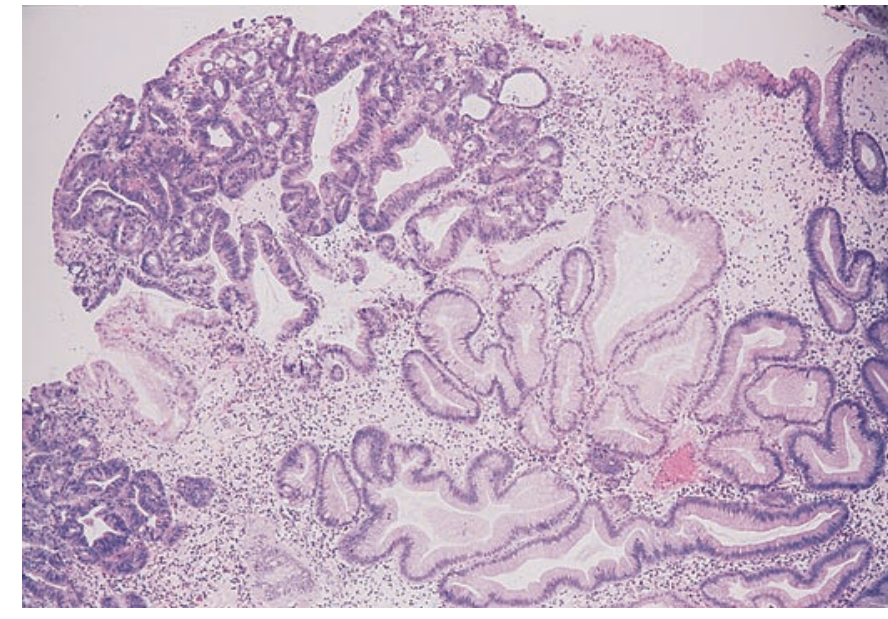

Figure 2 A photomicrograph of the resected specimen showed hyperplasia of the gastric foveolae. In addition, a focal intramucosal well-differentiated adenocarcinoma was visible in the left part of the lesion (hematoxylin and eosin; $\times 20$ ). The incidence of carcinoma found in hyperplastic foveolar polyps is reported to be between $0 \%$ and $6.1 \%$, and the development of cancer in hyperplastic polyps that are smaller than $1 \mathrm{~cm}$ is particularly rare.

Corresponding Author

\section{A. Okano, M.D.}

Department of Gastroenterology, Tenri

Hospital

200 Mishima-cho

Tenri

Nara 632-8552

Japan

Fax: $\quad+81-743-625576$

E-mail: okano-a@tenriyorozu-hp.or.jp 